\title{
TENDÊNCIAS E OPORTUNIDADES PARA PESQUISAS EM BIOCOMBUSTÍVEIS
}

\author{
D. B. REZENDE e V. M. D. PASA \\ Universidade Federal de Minas Gerais, Departamento de Química \\ E-mail: bastos_rezende@hotmail.com
}

\begin{abstract}
RESUMO: Temas como aquecimento global, crédito de carbono, emissões veiculares e combustíveis renováveis não são novidade na pauta de pesquisadores e centros de pesquisas pelo mundo. A sustentabilidade deixou de ser um modismo para virar uma necessidade e a busca por soluções energéticas limpas tem tomado dimensões cada vez maiores no mundo. No Brasil, o biodiesel e o etanol já são amplamente utilizados em larga escala no transporte rodoviário. Porém, fatores como disponibilidade e preço das matérias-primas e a necessidade de desenvolvimento de biocombustiveis para outras aplicações, como a aviação, mantêm esforços de pesquisadores no desenvolvimento de novas rotas e novos biocombustíveis. Tendo em vista a importância do assunto, foi realizada uma pesquisa no banco de periódicos disponíveis no Portal de Periódicos CAPES/MEC com a finalidade de verificar as tendências e as oportunidades na área de biocombustiveis.
\end{abstract}

PALAVRAS-CHAVE: Biocombustível; Biomassa; Combustível renovável; Combustível de aviação; Combustível de segunda-geração.

\section{INTRODUÇÃO}

O interesse da humanidade por fontes alternativas de combustíveis, provenientes de matérias-primas renováveis, rejeitos industriais ou resíduos diversos, não é uma novidade. Com o esgotamento das fontes fósseis e os impactos de suas emissões na natureza, como o aquecimento global, os combustíveis fósseis vêm sendo substituídos, em menor ou maior escala, por combustíveis renováveis, como o biodiesel, o bioetanol, o biogás e as diversas fontes renováveis de geração de energia elétrica, como as energias eólicas e solares (Lora e Venturini, 2012). Porém, mesmo que o tema "biocombustíveis" não seja novidade, surgem, a cada ano, novos biocombustíveis, novos processos produtivos e novas matérias-primas nas pautas de pesquisadores em todo mundo. No Brasil, o biodiesel e o etanol já são amplamente utilizados em larga escala no transporte rodoviário. Todavia, fatores como disponibilidade e preço das matérias-primas e a necessidade de desenvolvimento de biocombustíveis para outras aplicações, como a aviação, mantêm esforços de pesquisadores no desenvolvimento de novas rotas e novos biocombustíveis. 
Quando se fala em pesquisa em biocombustíveis, deve-se pensar em todo o ciclo de vida do produto, a definição do escopo da aplicação, a identificação das matérias-primas promissoras, a logística da matéria-prima, o desenvolvimento de rotas tecnicamente viáveis, o estudo da viabilidade econômica, as etapas de purificação e refino, a logística do combustível, a compatibilidade com os materiais e com o ambiente ao qual o biocombustível estará exposto e, por fim, as emissões e impactos ambientais e sociais resultantes.

Um tema que se mantém como um foco de discussão desde os últimos anos e vem ganhando força a cada ano é a questão da concorrência entre alimentos e biocombustíveis. A produção de biocombustíveis utilizando-se matérias-primas que podem ser destinadas à produção de alimentos é alvo de crítica por parte dos pesquisadores dessas áreas. A questão é ainda mais grave em regiões em que a disponibilidade de terras para o plantio é restrita, como na Europa. Tendo isso em mente, muitos pesquisadores vêm se esforçando para desenvolver tecnologia para produção de biocombustíveis a partir de matérias-primas alternativas, como óleos residuais, resíduos sólidos e, principalmente, biomassa lignocelulósica (Somerville et al., 2010). A produção de combustíveis a partir de materiais lignocelulósicos, chamados de combustíveis de segunda geração, também pode ser realizada por rotas enzimáticas, como acontece no caso do etanol de segunda geração no Brasil. De acordo com o Boletim Mensal dos Biocombustíveis publicado pelo Ministério de Minas e Energia do Brasil, até dezembro de 2016 havia cinco plantas comerciais de produção de etanol de segunda geração no mundo (MME, 2016).

O Brasil possui duas plantas de produção de etanol de segunda geração em escala comercial (Raízen e Granbio) e uma em escala demosntrativa no Centro de Tecnologia Canavieira - CTC. A unidade da Raízen em Piracicaba, São Paulo, tem capacidade para 42 milhões de litros anuais e custou R $\$ 237$ milhões. De acordo com a empresa, há previsão de para construção de mais sete plantas de etanol de segunda geração assim que a produção da primeira planta se tornar viável comercialmente, ou seja, quando o custo do etanol de segunda geração atingir o mesmo patamar que o de primeira geração (Raízen, 2015). Acredita-se que a viabilidade comercial dessas plantas só seja atingida com esforços específicos em pesquisa e desenvolvimento.

Existem diferentes rotas para converter a energia da biomassa em fluxo de energia final desejado, seja na forma de calor, combustível ou energia elétrica. A pirólise é a mais difundida dentre essas rotas por permitir o processamento descentralizado, evitando-se gastos com a logística de matéria-prima para grandes centrais. A pirólise é a transformação de uma matéria orgânica em outra, através de aquecimento em atmosfera inerte. Essa rota foi abordada vários trabalhos, com utilização de diferentes biomassas como o eucalipto, fibras de coco, bagaço e pontas de cana-de-açúcar, casca de arroz e outros resíduos da agroindústria (Furimsky, 2013).

Enquanto em anos anteriores o biodiesel e o bioetanol eram os principais biocombustíveis dentre os trabalhos, hoje, outro tipo de combustível tem aparecido com maior frequência, os chamados combustíveis drop in. Diferentemente do biodiesel e do bioetanol, os combustíveis drop in são bio-hidrocarbonetos idênticos aos seus equivalentes fósseis, em termos de estrutura química. Dessa forma, não há necessidade de qualquer mudança nos motores atuais. Assim como na pirólise, existem várias rotas para a produção 
dos combustíveis drop in. As mais conhecidas são: produção de biocombustível por FischerTropsh, processo certificado em Agosto de 2009; biocombustíveis produzidos por hidroprocessamento, como HEFA (Hydro-treated esters and fatty acids) e HRJ (hydroprocessed renewable Jet); conversões de alcoóis a combustíveis, conhecido como alcohol-tojet (ATJ), já produzido em escala comercial; fermentação de açucares para produção de isoparafinas (SIP) (Wang e Tao, 2016). No Brasil, a Amyris Biotechnologies investiu em uma planta de demonstração de produção diesel verde pela rota SIP.

Outro conceito importante é o de biorrefinarias. O conceito de produzir produtos a partir de commodities agrícolas, como a biomassa, não é novo. No entanto, utilizar a biomassa como insumo na produção de vários produtos de maneira similar a uma refinaria de petróleo é relativamente novo. Seu principal objetivo é transformar os materiais biológicos em produtos utilizáveis nas indústrias de transformação usando uma combinação de tecnologias e de processos biotecnológicos. As biorrefinarias não estão limitadas à produção de biocombustíveis, embora essa produção seja o core business dessa tendência. Além dos combustíveis, as biorrefinarias produzem compostos químicos básicos e especiais, biopolímeros, biolubrificantes, biorresinas, etc. (Nitzsche et al., 2016).

O uso da lignina, gerada como resíduo na indústria de polpa celulósica e na indústria de etanol celulósico (etanol de segunda geração) tem sido bastante estudado. Enquanto processos de craqueamento (térmico ou catalítico) podem levar à produção de biocombustíveis, processos de liquefação levam a biopolímeros de interesse da indústria (Furimsky, 2013).

O investimento de companhias aéreas e fabricantes de aeronaves em um combustível de aviação mais limpo, como o bioquerosene, é uma realidade. Notícias de companhias que fazem voos testes com combustíveis alternativos são frequentes (Plano de Voo para Biocombustíveis de Aviação no Brasil: Plano de Ação, 2013). Juntamente com esses investimentos, surgem também novas necessidades. $O$ desenvolvimento de novas metodologias de análises, o investimentos em laboratórios de certificação de biocombustíveis, estudos de viabilidade e scale up de novos processos e estudo de compatibilidade de biocombustíveis com materiais, sobretudo polímeros e elastômeros. Um trabalho da França em parceria com uma empresa fabricante de aeronaves apresentou um estudo de compatibilidade entre materiais atualmente utilizados em aeronaves e materiais alternativos, visando uma formulação ótima desses biocombustíveis (Amara et al., 2016).

A aviação é responsável por aproximadamente $2 \%$ das emissões de dióxido de carbono causadas pelo homem, com projeções de atingirem um nível de 3\% até o ano 2030 . Mesmo que esse percentual seja pequeno, a indústria de aviação se comprometeu a atingir um crescimento neutro até 2020 e de reduzir as emissões de dióxido de carbono em $50 \%$, em relação ao ano de 2005, até 2050 (Plano de Voo para Biocombustíveis de Aviação no Brasil: Plano de Ação, 2013).

Outro aspecto importante quando se fala em bioquerosene para aviação, são as propriedades a frio. Em grandes altitudes, os combustíveis estão sujeitos a baixíssimas temperaturas e, por razões óbvias, os combustíveis devem manter suas propriedades fluidodinâmicas para o bom funcionamento da aeronave. Mistura de hidrocarbonetos de diferentes fontes é alternativa para se atingir este requisito técnico (Silva et al., 2016). 
Apesar de haver viabilidade técnica em algumas rotas de produção de biocombustíveis de aviação e já existir algumas plantas industriais operando pelo mundo, sabe-se que esses processos ainda não possuem viabilidade comercial. Parte dessa inviabilidade está associada às elevadas pressões de hidrogênio e temperaturas dos processos atuais, o que tornam a operação dispendiosa e perigosa (Wang, 2016). Atualmente, as usinas em escala comercial existentes produzindo biocombustíveis de aviação pela rota HEFA são alocadas juntamente com refinarias de petróleo e plantas químicas devido à disponibilidade de insumos e utilidades e semelhança entre os processos. Como exemplo, citam-se as usinas da Neste Oil, com duas unidades na Finlândia, cada uma com capacidade produtiva de 238 dam $^{3} /$ ano de diesel verde, uma em Singapura e uma nos Países Baixos, ambas com capacidade produtiva de $1000 \mathrm{dam}^{3} /$ ano de diesel verde.

Congressos internacionais são sempre relevantes para se avaliar as tendências tecnológicas e a fronteira de conhecimento de uma área de pesquisa. Aconteceu em São Paulo, entre os dias 29 e 31 de Agosto, o $2^{\circ}$ Congresso Internacional de Biocombustíveis e Bioenergia. O evento contou com representantes de toda parte do mundo. As apresentações de trabalhos foram divididas nas seguintes sessões: Biomassa e Biocombustíveis de Alga; Biodiesel, Biogás e Bioetanol; Alimentação vs Combustíveis, Biorrefinarias e Bioenergia. As sessões mostraram o que tem sido pesquisado em termos de biocombustíveis na atualidade.

Um assunto de destaque neste congresso foi o conceito de biorrefinaria. As biorrefinarias possuem grande potencial de negócio no Brasil devido à vasta biodiversidade encontrada no país. Resíduos agroindustriais como os gerados na cultura do milho, arroz, trigo, dentre outros, derivados de atividades de produção de celulose, álcool, serrarias, são excelentes fontes de biomassa para as biorrefinarias. Dentre os assuntos abordados na sessão sobre biorrefinarias no Congresso de Biocombustíveis estão a gaseificação de biomassa para produção de energia elétrica, produção de carbono derivado de biomassa lignocelulósica para suporte de catalisadores, produção de bioenergia de resíduos florestais na África do Sul, produção de bioenergia no Paquistão e biorrefinarias com aproveitamento de resíduos de atividades florestais no Canadá. Outro tema amplamente discutido no congresso foi a produção de biocombustíveis através da pirólise de diferentes biomassas (2nd International Congress and Expo on Biofuels \& Bioenergy, 2016).

O Portal de Periódicos CAPES/MEC foi criado pelo Ministério da Educação (MEC) e pela Coordenação de Aperfeiçoamento de Pessoal de Nível Superior (CAPES) no ano de 2000, com o objetivo de fortalecer a pós-graduação no país. Ao final de 2015, o portal registrava 37.818 periódicos disponíveis e mais de 266.272 documentos eletrônicos, dentre patentes, capítulos de livros, anais, manuais e outros (Portal de Periódicos CAPES/MEC, 2016). Considerando a relevância do tema, o presente trabalho visou à realização de um estudo de tendências e oportunidades na área de combustíveis utilizando o Portal de Periódicos CAPES/MEC como fonte de dados. 


\section{MATERIAIS E MÉTODOS}

Para se avaliar quantitativamente as tendências na área de biocombustíveis, foi realizada uma pesquisa no banco de periódicos da Capes, Portal de Periódicos CAPES/MEC. Foram pesquisadas publicações de todo tipo no último ano (de seis de setembro de 2015 a seis de setembro de 2016). Foram realizadas 1128 buscas de palavras consideradas pelos autores como chaves nas pesquisas em biocombustíveis, contidas nos títulos dos artigos. Usou-se um total de 48 palavras, sempre pesquisadas em duplas, para se evitarem as buscas muito genéricas, como "vegetable". Assim, cada pesquisa foi realizada por pares de palavras contidas no título do periódico, num total de 48 palavras consideradas chaves dentro do macrotema "biocombustíveis". Por exemplo, a palavra "vegetable" nunca foi pesquisada sozinha, mas foi pesquisada juntamente com "biodiesel", "pyrolysis" e todas as demais 47 palavras-chaves utilizadas nesse trabalho (apresentadas em pares nas Figuras 1 e 2). $\mathrm{O}$ interesse da humanidade por fontes alternativas de combustíveis, provenientes de matériasprimas renováveis, rejeitos industriais ou resíduos diversos, não é uma novidade.

\section{RESULTADOS E DISCUSSÃO}

Os resultados de todas as buscas realizadas foram apresentados nas Figuras 1 e 2. A frequência de resultados das buscas no Portal de Periódicos CAPES/MEC refrente aos pares de palavras apresentadas na primeira coluna e na primeira linha da tabela é representada qualitativamente pela cor do quadrado relativo à interseção de linhas e colunas. Quanto mais escura a cor do quadro, maior o número de artigos encontrados contendo as duas palavras no título do artigo. O número no interior do quadrado refere-se à quantidade de artigos encontrado nessa mesma busca. Como exemplo, foram encontrados 214 artigos contendo ambas as palavras "biomass" e "waste" no seu título. Os quadrados da diagonal marcados com "x" são interseções de uma mesma palavra e, portanto, não pesquisados.

Analisando os resultados apresentados nas Figuras 1 e 2, observa-se grande concentração de publicações nas áreas de catálise heterogênea, biodiesel, biomassa, extração, aproveitamento de resíduos e materiais renováveis, cinética, scale up e caracterização. Entre os combustíveis, as maiores frequências de publicações no último ano estão relacionadas àqueles combustíveis obtidos através de pirólise de biomassa, biodiesel e etanol de segunda geração.

A grande concentração de pesquisa envolvendo catalisadores heterogêneos se justifica pela busca de processos que gerem menos efluentes industriais, como o efluente gerado nas etapas de purificação do biodiesel produzido via catálise homogênea, necessárias para a remoção do catalisador. Além disso, a possibilidade de recuperação e reutilização do catalisador também é ecologicamente favorável. A maior concentração de trabalhos envolvendo catálise heterogênea ainda é visando à produção do biodiesel (biodiesel, transesterificação e esterificação). Este, por sua vez, continua sendo o biocombustível mais pesquisado, não somente sua produção, mas também em métodos de caracterização, simulações, cinéticas de reação e análise de ciclo de vida. A saturação do tema faz com que algumas revistas especializadas não permitam a publicação de artigos sobre produção de biodiesel via catálise homogênea ou estudo de estabilidade desse combustível. A Figura 3 apresenta o número de publicações contendo a palavra "biodiesel" no título desde 2000. 
Verifica-se um crescimento no número de publicações com seu ápice em 2014, apresentando queda a partir de 2015.

A busca por novas matérias-primas para produção de biocombustível se torna evidente através dos elevados números de artigos biomassa, resíduos e rejeitos. Essa alta frequência está relacionada às pesquisas em combustíveis de segunda geração, com matérias-primas lignocelulósicas, e produtos de pirólise. O par de palavras "lingnocellulosic" e "biomass" resultou em 153 artigos no último ano, enquanto o par "pyrolysis" e "biomass" resultou em 191 artigos.

A preocupação com a destinação ecologicamente correta é evidenciada no grande número de trabalhos publicados utilizando-se resíduos e rejeitos como matérias-primas. Além da destinação correta, agregar valor aos resíduos e rejeitos pode tornar um processo economicamente viável. Os combustíveis hidrogenados apresentaram um crescimento recente no interesse dos pesquisadores, mas ainda possuem espaço para crescimento.

Além das tendências, representadas pelos quadrados mais escuros, notam-se oportunidades nas áreas de combustíveis desoxigenados e isomerizados, Alcohol-to-jet e combustível de aviação, identificadas nos quadros mais claros. Outro tópico que merece destaque é a Análise de Ciclo de Vida. A ferramenta é bastante utilizada para combustíveis já consolidados, como o etanol e o biodiesel, mas possui oportunidades para trabalhos com o biocombustível de aviação e os biolubrificantes.

Atualmente, o combustível de aviação utilizado no Brasil é integralmente de origem fóssil. Dadas as metas traçadas pela indústria de aviação de redução das emissões de dióxido de carbono, as pesquisas desses combustíveis ainda são incipientes, fato que pode ser observado pelo número de publicações com as palavras "desoxigenação" e "isomerização", processos essenciais para a produção de biocombustíveis de aviação que se enquadrem nos requisitos internacionais desses combustíveis, sobretudo com relação às propriedades a frio.

Ainda como oportunidades, verifica-se a carência de pesquisas na área de biolubrificantes, com apenas quatro publicações. Há alguns anos, estudos utilizando óleo vegetal, modificado ou não modificado, foram realizados na intenção de se utilizar essa matéria-prima como lubrificante, substituindo os óleos minerais e sintéticos utilizados atualmente, ambos provenientes do petróleo. Devido aos resultados insatisfatórios, sobretudo com relação à baixa estabilidade térmica do produto, esse tema tem sido deixado de lado nos últimos anos. Com um grande mercado a disposição, a pesquisa em biolubrificantes surge como uma grande oportunidade. Assim como os combustíveis drop in, que são quimicamente idênticos aos seus correspondentes fósseis, biolubrificantes drop in podem ser desenvolvidos por meio de técnicas semelhantes. Não se encontra na literatura cientifica qualquer trabalho nesse sentido. 


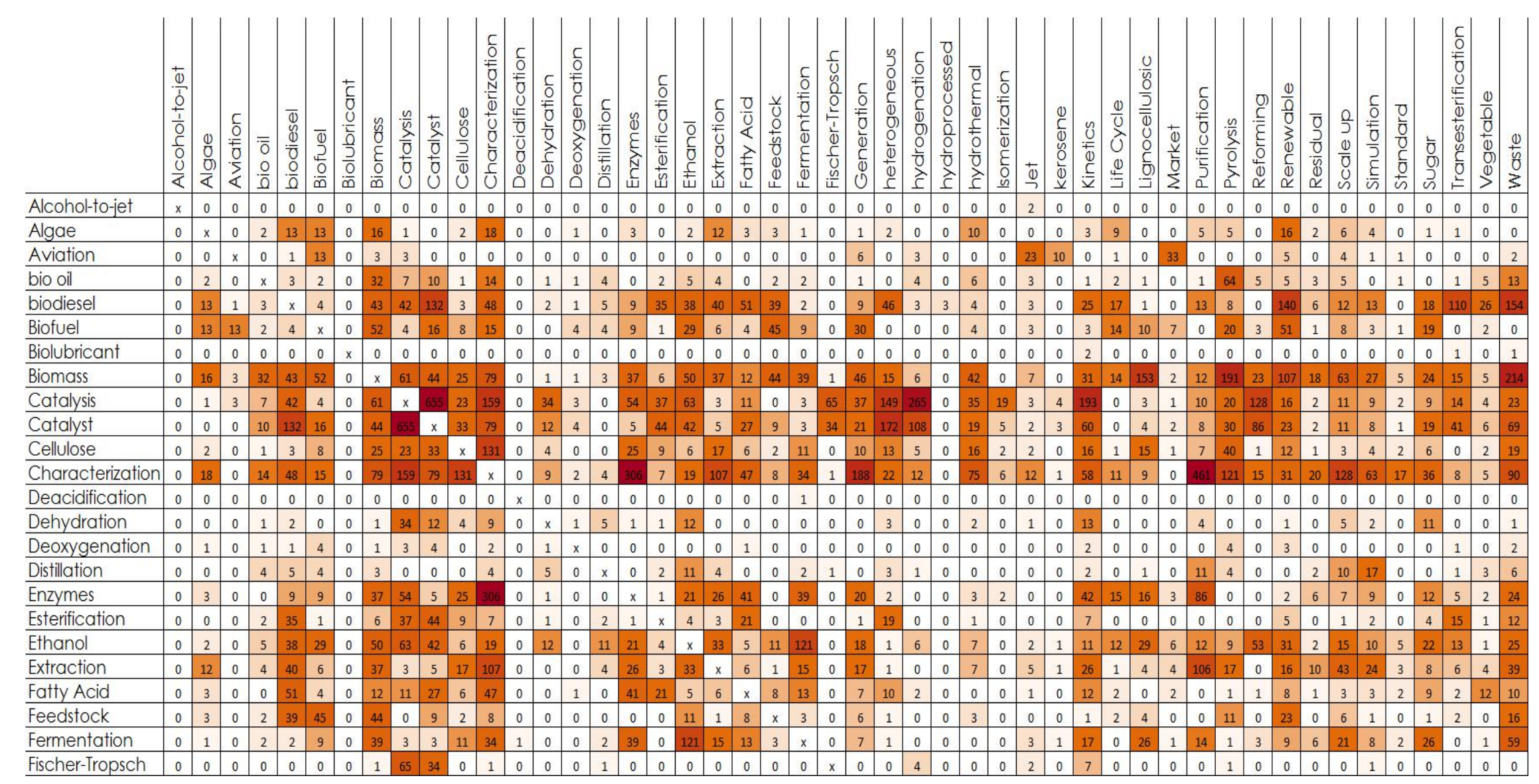

Figura 1 - Matriz de resultados das buscas dos pares de palavras-chaves (primeira parte). 


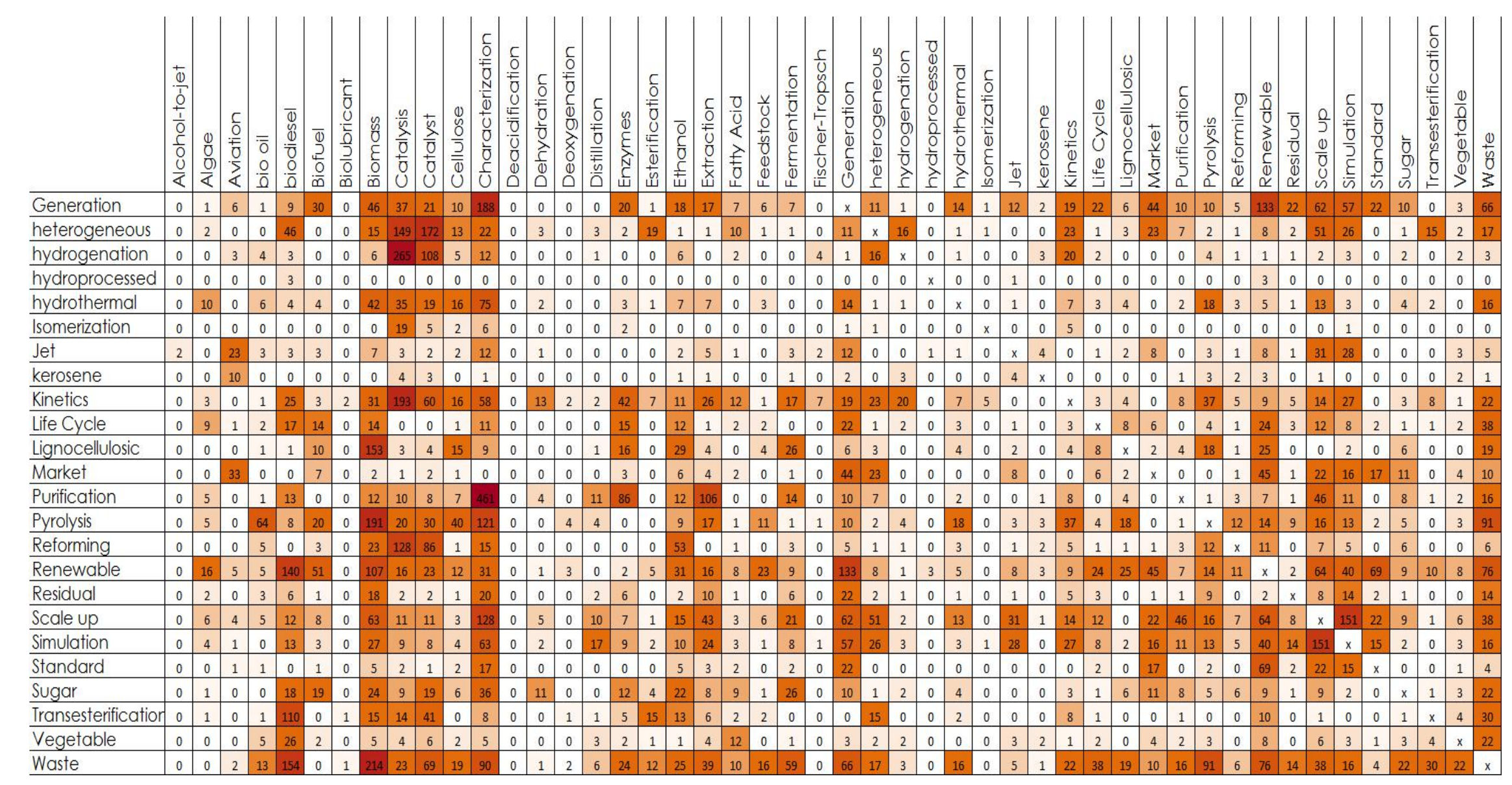

Figura 2 - Matriz de resultados das buscas dos pares de palavras-chaves (segunda parte). 


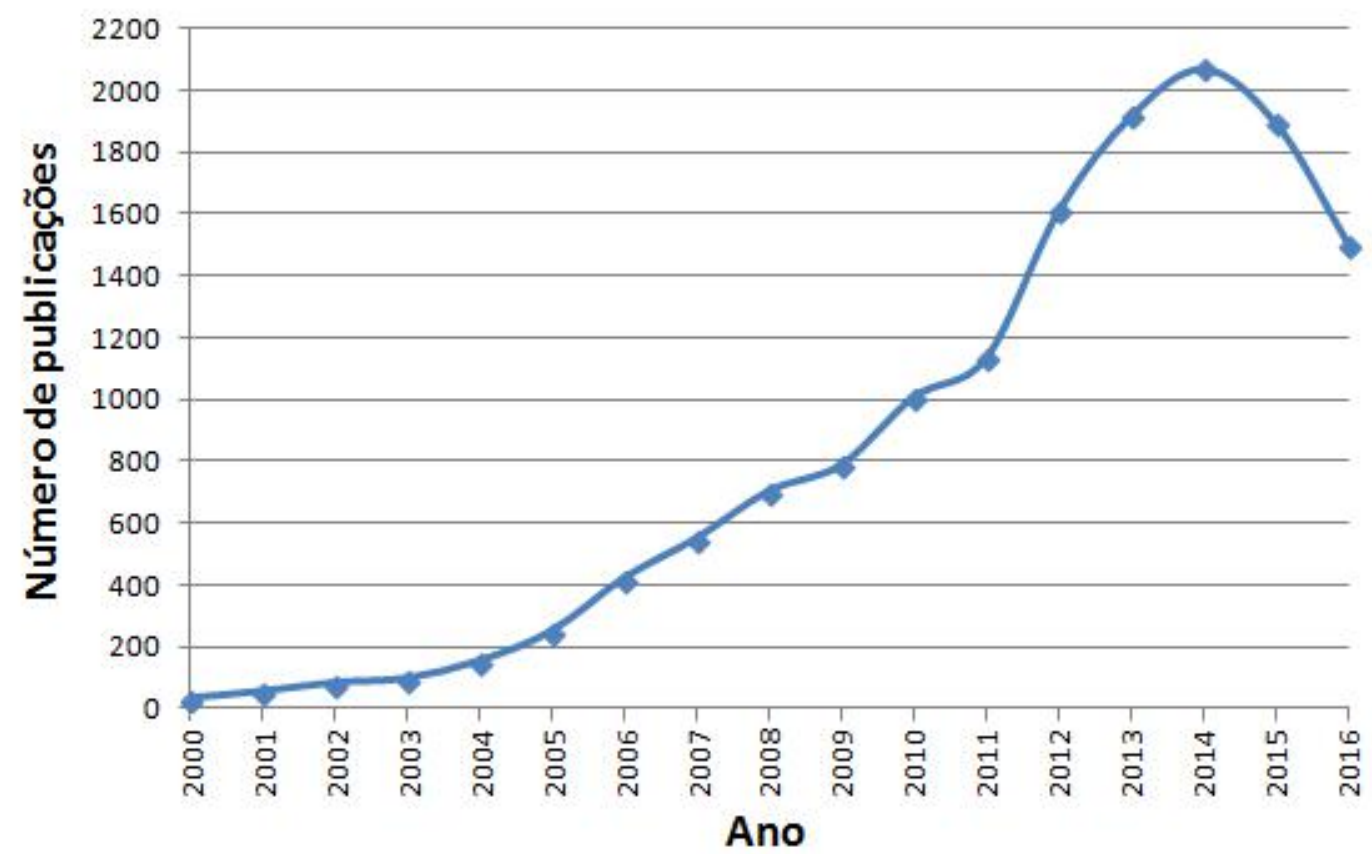

Figura 3 - Evolução na publicação de artigos contendo a palavra "biodiesel" no título.

A Figura 4 apresenta o somatório dos resultados de todas as buscas realizadas nesse trabalho, considerando-se as principais palavras-chaves na área de biocombustíveis, na opinião dos autores. Por exemplo, a primeira barra do gráfico, "biomass", representa a soma de todas as buscas nas quais, uma das palavras do par de palavras pesquisado era "biomass". Dessa forma, tem-se uma visão geral da frequência de cada tema pesquisado, independentemente do subtema.

Analisando-se a Figura 4, corroboram-se as afirmações anteriores, de que as pesquisas contendo as palavras "biomassa", "biodiesel" e "pirólise" são as com maior concentração de publicações. Verificam-se concentrações elevadas também nas áreas de hidrogenação, celulose e lignocelulose. Identificam-se oportunidades, pelo baixo número de pesquisas e pelo contexto atual da sociedade, nas pesquisas em combustíveis de aviação, seja no processo produtivo, seja na purificação do produto, na sua caracterização e uso. Todas as rotas de produção de biocombustíveis drop in, em especial o bioquerosene, foram pouco exploradas no último ano (Fischer Tropsch, hidroprocessamento, desoxigenação e isomerização e alcohol-to-jet). 


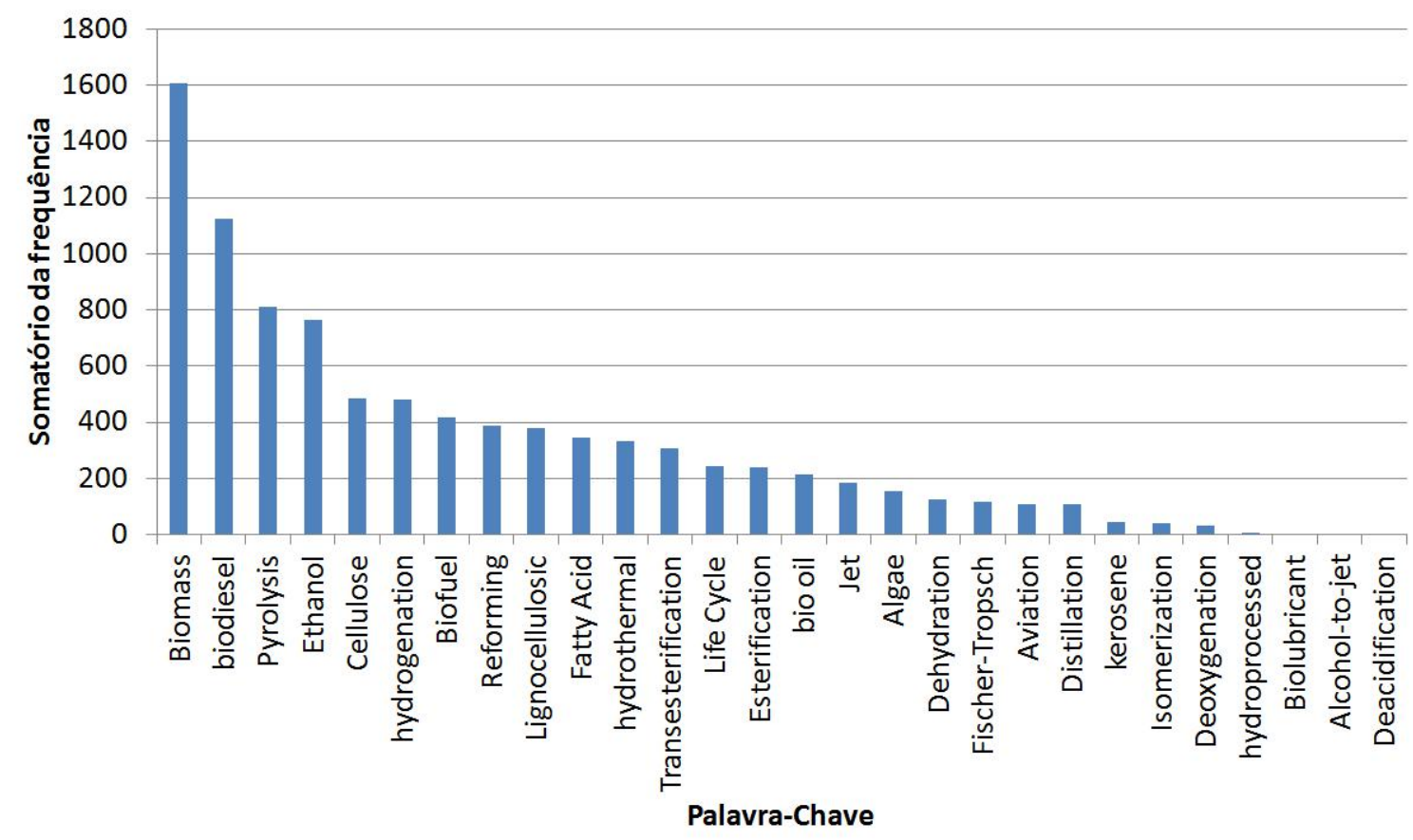

Figura 4 - Somatório dos resultados de busca das principais palavras-chaves.

\section{CONCLUSÃO}

O trabalho realizado, através da análise de 1128 pesquisas no banco de dados da Capes referentes às publicações do último ano (setembro de 2015 a setembro de 2016), mostrou-se eficiente na identificação de tendências tecnológicas nas áreas de biocombustíveis. Também foi possível identificar as oportunidades de pesquisas ainda pouco investigadas no que tange à bioenergia. Os resultados de tendência obtidos neste trabalho são corroborados pelos assuntos discutidos e trabalhos apresentados no 2nd International Congress and Expo on Biofuels \& Bioenergy.

De forma geral, as publicações estão mais concentradas nas áreas de biodiesel, combustíveis hidrogenados e, principalmente, na investigação de biomassas e material lignocelulósico como matéria-prima para a produção de biodiesel. Como oportunidades, citam-se as pesquisas relacionadas a biocombustíveis de aviação e biolubrificantes.

\section{AGRADECIMENTOS}

Agradecemos o apoio financeiro da Agência Nacional do Petróleo, Gás Natural e Biocombustíveis - ANP, da Financiadora de Estudos e Projetos - FINEP e do Ministério da Ciência, Tecnologia e Inovações e Comunicações por meio do Programa de Formação de Recursos Humanos da ANP para o Setor Petróleo e Gás - PRH-ANP/MCT. 


\section{REFERÊNCIAS}

2nd International Congress and Expo on Biofuels \& Bioenergy. August 29-31, 2016, São Paulo, Brazil. Journal of Fundamentals of Renewable Energy and Applications. Disponível em: http://biofuels-bioenergy.conferenceseries.com/call-for-abstracts.php. Acessado em: 16 de novembro de 2016.

AMARA, A. B.; KAOUBI, S.; STARCK, L. Toward an optimal formulation of alternative jet fuels: Enhanced oxidation and thermal stability by the addition of cyclic molecules. Fuel. Vol 173, pag. 98-105, 2016.

FURIMSKY, E. Hydroprocessing challenges in biofuels production. Catalysis Today. Vol 217, pag 13-66, 2013.

LORA, E. E. S.; VENTURINI, O. J. Biocombustíveis. Volume 1, Editora Interciência. Rio de Janeiro, 2012.

MME - Boletim Mensal dos Biocombustíveis, Ministério de Minas e Energia, Edição $\mathrm{N}^{\circ}$ 106 de dezembro de 2016.

NITZSCHE, R.; BUDZINSKI, M.; GRÖNGRÖFT, A. Techno-economic assessment of a wood-based biorefinery concept for the production of polymer-grade ethylene, organosolv lignin and fuel. Bioresource Technology. Vol. 200, pag. 928-939, 2016.

Plano de Voo para Biocombustíveis de Aviação no Brasil: Plano de Ação. Boeing, Embraer, Unicamp e Fapesp, São Paulo, 2013. Disponível em: http://www.fapesp.br/publicacoes/plano-de-voo-biocombustiveis-brasil-pt.pdf?x=2, Acessado em setembro de 2016.

Portal de Periódicos CAPES/MEC. Disponível em: www.periodicos.capes.gov.br. Acessado em: 13/10/2016.

Raízen - Raízen inaugura primeira unidade de etanol de segunda geração, matéria publicada no site em julho de 2015. Disponível em: http://www.raizen.com.br/raizen-inauguraprimeira-unidade-de-etanol-de-segunda-geracao. Acessado em 25 de abril de 2017.

SILVA, L. N.; FORTES, I. C. P.; SOUSA, F. P.; PASA, V. M. D. Biokerosene and green diesel from macauba oils via catalytic deoxygenation over Pd/C. Fuel. Vol 164, Pag. 329-338, 2016.

SOMERVILlE, C.; YOUNGS, H., TAYLOR, C., DAVIS, S. C., LONG, S. P. Feedstocks for Lignocellulosic Biofuels. Science, Vol 329, Issue 5993, 2010.

WANG, W.; TAO, L. Bio-jet fuel conversion technologies. Renewable and Sustainable Energy Reviews. Vol 53, pag. 801-822, 2016.

WANG, W. Techno-economic analysis of a bio-refinery process for producing Hydroprocessed Renewable Jet fuel from Jatropha. Renewable Energy. Vol 95, pag. 63-73, 2016. 


\title{
TRENDS AND OPPORTUNITIES IN RESEARCH ON BIOFUELS
}

\author{
D. B. REZENDE and V. M. D. PASA \\ Universidade Federal de Minas Gerais, Department of Chemistry \\ E-mail: bastos_rezende@hotmail.com
}

\begin{abstract}
Topics such as global warming, carbon credit, vehicle emissions and renewable fuels are not new on the agenda of researchers and the world research centers. Sustainability is no longer a fad, becoming a necessity. The search for clean energy solutions has gained more space and relevance in the world. In Brazil, biodiesel and ethanol are already widely used in road transport. However, factors such as availability and price of raw materials and the need to develop biofuels for other applications, such as aviation, maintain efforts to develop new routes and new biofuels. Given the importance of the subject, a survey was conducted in periodic database available on Portal de Periódicos CAPES/MEC, a Brazilian website developed by the federal government to support researchers, in order to verify the trends and opportunities in biofuels.
\end{abstract}

KEYWORDS: Biofuels; Biomass; Renewable Fuel; Aviation Fuel; Second Generation Fuel. 